\title{
Thixotropy and structural breakdown properties of self consolidating concrete containing various supplementary cementitious materials
}

\author{
Reza Saleh Ahari ${ }^{\mathrm{a}, *}$, Tahir Kemal Erdem ${ }^{\mathrm{b}}$, Kambiz Ramyar ${ }^{\mathrm{a}}$ \\ ${ }^{a}$ Department of Civil Engineering, Ege University, Izmir, Turkey \\ ${ }^{\mathrm{b}}$ Department of Civil Engineering, Izmir Institute of Technology, Izmir, Turkey
}

\section{A R T I C L E I N F O}

\section{Article history:}

Received 9 September 2014

Received in revised form 8 January 2015

Accepted 3 March 2015

Available online 11 March 2015

\section{Keywords:}

Self-consolidating concrete

Supplementary cementitious materials

Thixotropy

Breakdown

Drop in apparent viscosity

Yield value at rest

\begin{abstract}
A B S T R A C T
In this study, thixotropy and structural breakdown of 57 self-consolidating concrete (SCC) mixtures containing various supplementary cementitious materials (SCM) were investigated by different approaches. The effects of SCM type and content on high range water reducer demand and plastic viscosity were also studied. For these purposes, various amounts of silica fume (SF), metakaolin (MK), Class F fly ash (FAF), Class C fly ash (FAC) and granulated blast-furnace slag (BFS) were utilized in binary, ternary, and quaternary cementitious blends in three water/binder $(\mathrm{w} / \mathrm{b})$ ratios. Results showed that except BFS, use of SCM in SCC mixtures increased thixotropy values in comparison with the mixtures containing only portland cement (PC). Good correlations were established between structural breakdown area and drop in apparent viscosity values for all $\mathrm{w} / \mathrm{b}$ ratios. The different methods used to evaluate the thixotropy and structural breakdown got more consistent with each other as $\mathrm{w} / \mathrm{b}$ decreased.
\end{abstract}

๑) 2015 Elsevier Ltd. All rights reserved.

\section{Introduction}

Utilization of supplementary cementitious materials (SCM) in concrete has a tendency to increase by the future in order to provide greater sustainability in construction industry. SCM such as fly ash (FA), granulated blast-furnace slag (BFS) and silica fume (SF) are widely used in self-consolidating concrete (SCC) due to their several advantages. First of all, the high amount of paste requirement for better flow of SCC is easily achieved by SCM, which is superior to using only portland cement (PC). Also utilization of these SCM in SCC reduces the demand for PC, fine fillers and viscosity-enhancing chemical admixtures in SCC. Many studies [15] reported that use of SCM in SCC not only improves the mechanical, durability and long term properties of concrete, but also helps to adjust the rheological and thixotropic properties as well as stability of the fresh SCC for a given application. In other words, plastic viscosity or stability specifications can be tailored according to the desired performance in a variety of civil engineering applications by the utilization of SCM. Additionally, use of by-product SCM, like FA and BFS, can decrease the cost of SCC and the amount of the $\mathrm{CO}_{2}$ production related to the use of $\mathrm{PC}$ in concrete. Therefore, use of SCM has become very important in SCC $[6,7]$.

\footnotetext{
* Corresponding author. Tel.: +90 23238860 26; fax: +90 2323425629 .

E-mail address: rsalehahari@mail.ege.edu.tr (R.S. Ahari).
}

Despite the above-mentioned advantages of SCM in SCC, they may present some deleterious effects on SCC properties compared to the plain SCC containing no SCM. For instance for a constant slump flow, MK may significantly increase plastic viscosity [8] and impair a sharp fall in the workability of fresh concrete although it can considerably reduce the permeability [3] of SCC. On the contrary, BFS may improve workability but it may decrease plastic viscosity of SCC $[9,10]$. Plastic viscosity of SCC mixtures containing SF could be similar or lower than of the control mixture without any SCM at constant slump flow values while stability and durability aspects are improved $[4,5,8]$. In addition, replacement of PC by FA in SCC mixtures can increases plastic viscosity [11] but may significantly decrease early strength values [12].

A high amount of plastic viscosity can reduce concrete flowability and workability, whereas a very low viscosity can accelerate the speed of segregation [13]. Moreover, a concrete with a high degree of thixotropy may show high segregation resistance [5] and decrease lateral pressure exerted on the formwork system [14] while high thixotropy may lead to an increase in entrapment of air in fresh concrete and formation of lift lines in multilayer casting [15]. Such opposite effects may be remedied by the combined use of the SCM. Therefore, combinations of SCM in ternary and quaternary cementitious blends have found significant importance in the presented study.

Although a number of studies about the effects of SCM on the fresh and hardened properties of SCC have been found in the 
literature, the effect of using SCM on the thixotropic properties were discussed only in limited number of studies $[2,5,16]$. Moreover, the potential benefit of using various amounts of SCM in ternary and quaternary combinations with PC on rheological and thixotropic properties of SCC is not well documented. Thus, the effects of different blends of SCM on rheological and thixotropic properties of SCC are presented in this study.

Thixotropy can be defined as a gradual decrease of the viscosity under shear stress followed by a gradual recovery of structure when the stress is removed [17]. The thixotropic behavior of cement paste is related to coagulation, dispersion and re-coagulation of the cement particles [18-20]. Coagulation is a result of the total potential energy interaction between them, which originates from the combined forces of van der Waals attraction, electrostatic repulsion and steric hindrance $[19,21,22]$.

Tattersall and Banfill [21] explained the structural breakdown as follows: When cement particles and water come together, a hydrate membrane immediately covers and links the particles. If the cement paste is sheared, the linkages between them may be broken, separating the particles. The breaking of linkages was considered to be an irreversible process and thus non-thixotropic [21,23].

There are several ways of studying the thixotropy and structural breakdown. By gradually increasing and then decreasing the angular velocity of the viscometer vane, the corresponding torque values will form a hysteresis loop if the mixture is thixotropic. The area between the up and down curves can quantify the thixotropy $[21,24,25]$. A more widely used method to quantify the thixotropy and structural breakdown is to keep the shear rate constant and observe the change (decrease) in the corresponding torque values in time [21]. This approach can be repeated for several constant shear rates to study the behavior over a wider range of shear rates, enabling a more comprehensive evaluation $[5,26]$. The thixotropic behavior of the cementitious materials was also studied by evaluating the static yield strengths of the mixtures determined at very low shear rates [27]. Roussel defined a so-called "thixotropy index" as the ratio of the shear stress at rest to the characteristic time of flocculation [14]. The modeling of the time-dependent behavior of the cementitious materials have attracted the attention of many researchers [20-24]. In a recent research, Wallewik [23] showed, by both his model and experimental work, that the time-dependent behavior is governed by both thixotropy (combination of coagulation, dispersion and re-coagulation of the cement particles) and structural breakdown (breaking of chemically formed linkages between the particles). Very detailed reviews for thixotropy and structural breakdown can be found in $[19,24,28,29]$.

In recent years, the study of thixotropy and structural breakdown of SCC has become an interesting area of research owing to the fact that it would help concrete technologists to predict some aspects such as the static stability, segregation resistance, formwork pressure and its decay after casting, air entrapment, surface quality, interlayer bond strength between consecutive concrete layers and pumpability of concrete [15,30-34].

SCC behaves thixotropically showing good segregation resistance and low lateral pressure on formwork whereas it probably can increase entrapped air in fresh concrete and lift lines in multilayer casting, reducing bond strength between layers $[15,31,35]$. Therefore, for a given application the mixture parameters of SCC should be adjusted to achieve a given profile of thixotropic properties that can take into account the various requirements. Many parameters such as $\mathrm{w} / \mathrm{b}$ ratio [36], binder type and content [2,37], aggregate characteristics and content [38] can affect the rheological properties, thixotropic and structural breakdown behavior of SCC. Besides the type and dosage of high-range water-reducing admixture (HRWR) [36], type and concentration of viscosity-modifying admixture (VMA) [39] as well as use of set-modifying admixtures [30] are important parameters in this respect.

Cementitious materials characteristics such as concentration, packing density, fineness and incorporation of SCM such as FA, SF and BFS are among the factors that affect the rheology and thixotropy of concrete [14,21,40]. Roussel et al. [41] reported that high thixotropy value in the mixtures containing SCM, like fine silica or limestone particles, is related to nucleation effect of these materials in PC mixtures. In fact, the increase in thixotropy without any workability loss can be obtained if the mixing power is sufficient to break the additional $\mathrm{C}-\mathrm{S}-\mathrm{H}$ bonds created by these products. It was reported that utilization of SCM in concrete increases the internal friction and hence attractive forces among solid particles, which in turn, increase the degree of physical and chemical bonds during cement hydration $[14,21,40]$.

Assaad [2,5] studied the rheological and thixotropic properties of SCC containing SF, BFS and FA. It was reported that mixtures containing a binary cement $(\mathrm{PC}+\mathrm{SF})$, a ternary cement $(\mathrm{PC}+\mathrm{SF}+\mathrm{FA})$ and a quaternary cement (PC + SF + FA + BFS) showed lower plastic viscosity and higher thixotropy values than corresponding plain SCC mixtures in the time interval between 0 and $30 \mathrm{~min}$. However, reduction in the amount of thixotropy was observed in quaternary mixtures up to $150 \mathrm{~min}$. It was also reported that mixtures with higher amount of cement content and lower amount of aggregate showed lower thixotropy values.

In a more recent study, Rahman et al. [16] reported that the use of SF in SCC in the range of $2.5-7.5 \%$ by weight of cement did not influence the thixotropy significantly from that of the control mixture. However use of FA in the range of $5-10 \%$ by weight of cement was found to increase the thixotropy of the mixture considerably.

In this paper, the rheology, thixotropy and structural breakdown of SCC made with various amounts of SF, FA, MK and BFS as a partial replacement of PC were studied. The aim of the first part of this study is to evaluate the effect of using these SCM in binary, ternary, and quaternary cementitious blends on HRWR demand and rheology. In the second part, the effect of these SCM on the thixotropy and structural breakdown of SCC mixtures was evaluated by different approaches. The effects of the SCM were also compared to those of a VMA. A total of 57 SCC mixtures were designed to have three $\mathrm{w} / \mathrm{b}$ ratios with various binder contents. The measurements were made with a coaxial cylinder concrete rheometer.

\section{Research significance}

Rheology, thixotropy and structural breakdown of SCC have been recognized as important tools to be tailored to achieve a multifold set of engineering properties required for successful accomplishment and performance of the intended application. For a given application, the mixture's properties should be adjusted to achieve a given profile of static stability, segregation resistance, formwork pressure, air entrapment, surface quality and interlayer bond strength between consecutive concrete layers. Utilization of SCM in concrete can not only improve the mechanical and durability properties of the mixtures, but also improve rheological and thixotropic properties as well as stability of the fresh concretes [1-3,5]. Although a number of studies about the effects of using FA, SF and BFS on the fresh and hardened properties of SCC have been found in the literature, the effect of using these SCM on the rheological and thixotropic properties were discussed only in limited number of studies $[2,5,16]$. Moreover, the potential benefit of using various amounts of SCM in ternary and quaternary blends on thixotropic properties of SCC is not well documented. The study presented herein aims at filling these gaps in the literature. 


\section{Experimental methods}

\subsection{Materials}

The SCC mixtures studied in this study were prepared with an ordinary PC (CEM I 42.5 R), compliant to ASTM C 150 Type I [42]. SF, FAC, FAF, MK, and BFS were five SCM used in binary, ternary, and quaternary cementitious blends. The physical and chemical properties and particle-size distribution of PC, SF, FAF, MK, and BFS are presented in Table 1 and Fig. 1. Moreover, the particles of these SCM were inspected by a scanning electron microscope (SEM) as shown in Fig. 2. As seen in Fig. 1, SF is obviously the finest of all SCM. The next finer material was MK which was considerably different from the other SCM. In addition, the particle size distribution of PC, BFS, FAC and FAF were similar to each other. Crushed limestone aggregate with maximum particle size of $15 \mathrm{~mm}$ (0.59 in) and $4 \mathrm{~mm}$ (0.157 in), respectively for coarse and fine aggregate, were employed. The bulk specific gravity of the coarse and fine aggregates was 2.64 and 2.61, and their absorption capacities were $0.21 \%$ and $0.67 \%$, respectively. A polycarboxylate ether-based HRWR conforming to ASTM C494 Type F [43] with specific gravity of 1.06 and solid content of $28 \%$ was employed. A liquid polysaccharide based VMA with $39 \%$ solid content was utilized in some SCC mixtures.

\subsection{Mixtures proportions}

A total of 57 SCC mixtures having three $\mathrm{w} / \mathrm{b}$ ratios $(0.44,0.50$, and 0.56$)$ with various binder contents $\left(454.5 \mathrm{~kg} / \mathrm{m}^{3}(766.3 \mathrm{lb} /\right.$ $\left.\mathrm{y} \mathrm{d}^{3}\right), 400 \mathrm{~kg} / \mathrm{m}^{3}\left(674 \mathrm{lb} / \mathrm{y} \mathrm{d}^{3}\right)$ and $\left.357 \mathrm{~kg} / \mathrm{m}^{3}\left(602 \mathrm{lb} / \mathrm{y} \mathrm{d}^{3}\right)\right)$ and constant water content were designed. The mix proportions are summarized in Tables 2-4. For all SCC mixtures the fine aggregate-to-total aggregate ratio, by mass, was set at 0.53. The HRWR dosages used in the mixtures were adjusted to secure an initial slump flow of $650 \pm 10 \mathrm{~mm}$ (25.59 \pm 0.39 in). Three control mixtures were made with only PC as binder, whereas the other mixtures were made with binary $(\mathrm{PC}+\mathrm{SF}, \mathrm{PC}+\mathrm{FAC}, \mathrm{PC}+\mathrm{FAF}$, $\mathrm{PC}+\mathrm{MK}$ and $\mathrm{PC}+\mathrm{BFS})$, ternary $(\mathrm{PC}+\mathrm{SF}+\mathrm{BFS}, \mathrm{PC}+\mathrm{FAC}+\mathrm{BFS}$, $\mathrm{PC}+\mathrm{FAF}+\mathrm{BFS}$ and $\mathrm{PC}+\mathrm{MK}+\mathrm{BFS}$ ) and quaternary $(\mathrm{PC}+\mathrm{SF}+\mathrm{FAC}+\mathrm{BFS})$ cementitious blends by replacing a part of the PC with the SCM. The substitution levels were on mass basis by $4 \%, 8 \%$ and $12 \%$ for $\mathrm{SF}, 4 \%, 8 \%, 18 \%$ and $36 \%$ for $\mathrm{MK}, 18 \%$ and $36 \%$ for FA and only $18 \%$ for BFS. Furthermore, for each $\mathrm{w} / \mathrm{b}$ ratio, additional mixtures were prepared without any SCM but with a constant amount of VMA (Tables 2-4). The dosage of VMA was selected according to the recommended dosage range given by

Table 1

Physical and chemical properties of PC and SCM.

\begin{tabular}{|c|c|c|c|c|c|c|}
\hline & PC & SF & FAC & FAF & MK & BFS \\
\hline $\mathrm{CaO}(\%)$ & 64.06 & 0.25 & 36.56 & 3.24 & 0.3 & 35.2 \\
\hline $\mathrm{SiO}_{2}(\%)$ & 17.74 & 87.92 & 31.94 & 59.5 & 51.1 & 40.3 \\
\hline $\mathrm{Al}_{2} \mathrm{O}_{3}(\%)$ & 4.76 & 0.4 & 13.5 & 18.5 & 39.1 & 10.2 \\
\hline $\mathrm{Fe}_{2} \mathrm{O}_{3}(\%)$ & 3.17 & 0.35 & 4.09 & 6.96 & 2.15 & 0.67 \\
\hline $\operatorname{MgO}(\%)$ & 1.28 & 3.97 & 1.42 & 2.03 & 0.7 & 6.9 \\
\hline $\mathrm{SO}_{3}(\%)$ & 2.94 & 0.21 & 3.86 & 0.47 & 0.08 & 1.4 \\
\hline $\mathrm{K}_{2} \mathrm{O}(\%)$ & 0.8 & 0.81 & 0.94 & 1.93 & 1.78 & 0.97 \\
\hline $\mathrm{Na}_{2} \mathrm{O}(\%)$ & 0.45 & 1.79 & 1.1 & 1.27 & 0.11 & 1.12 \\
\hline Free lime $(\%)$ & 2.21 & - & 2.69 & 0.42 & - & - \\
\hline Other minor oxides (\%) & 0.64 & 1.43 & 0.91 & 1.26 & 0.88 & 1.34 \\
\hline Loss on ignition (\%) & 1.95 & 2.87 & 2.99 & 4.32 & 3.8 & 1.9 \\
\hline Specific gravity & 3.13 & 2.29 & 2.73 & 2.38 & 2.54 & 2.97 \\
\hline Blaine fineness $\left(\mathrm{cm}^{2} / \mathrm{g}\right)$ & 3310 & - & 3470 & 3220 & - & 3650 \\
\hline $\begin{array}{l}\text { Surface area B.E.T. } \\
\qquad\left(\mathrm{cm}^{2} / \mathrm{g}\right)\end{array}$ & - & 245,100 & - & - & 154,100 & - \\
\hline Residue $45 \mu \mathrm{m}(\%)$ & 4.2 & - & 17.4 & 19.5 & 0.4 & 1.3 \\
\hline
\end{tabular}

Notes: $1 \mathrm{~cm}^{2} / \mathrm{g}=0.488 \mathrm{ft}^{2} / 1 \mathrm{~b}$.

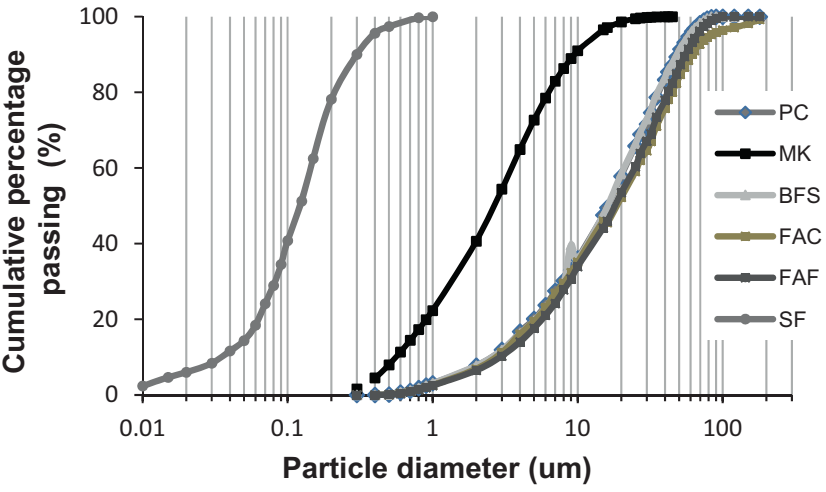

Fig. 1. Particle size distributions of PC and SCM.

the manufacturer. Rheology of SCC during its production depends on mixing efficiency, mixer type, mixing sequence, ambient temperature, etc. $[44,45]$. Therefore; these factors were kept constant throughout the study. The mixing procedure for concrete mixtures consisted of homogenizing the aggregate with $35 \%$ of the mixing water for $1 \mathrm{~min}$ in a batch of $20 \mathrm{~L}$ using a rotary planetary mixer. Cementitious materials with $40 \%$ of water were added following a rest period of $1 \mathrm{~min}$ to allow the saturation of the aggregates. Mixing continued $2 \mathrm{~min}$ and then the HRWR diluted with the remaining water was introduced gradually over $2 \mathrm{~min}$. Following 2 min of rest, the concrete was mixed for 3 additional min. The ambient temperature during mixing and testing was maintained at approximately $20 \pm 2{ }^{\circ} \mathrm{C}\left(68^{\circ} \mathrm{F}\right)$. The mixtures were designated according to the type and the amount of cementitious materials included. For example, 8SF18FAC18BFS shows the quaternary mixture containing $8 \% \mathrm{SF}, 18 \% \mathrm{FAC}$ and $18 \% \mathrm{BFS}$.

\subsection{Testing procedures}

The measurement of fresh SCC properties was started as soon as mixing of all materials was finished ( 9 min after the initial contact of water with cement). The slump flow values were represented by the mean diameter (measured from two perpendicular directions) of the concrete spread after lifting the standard slump cone. After a slump flow of $650 \mathrm{~mm}$ (25.59 in) was ensured, the rheological parameters were evaluated using a coaxial cylinder concrete rheometer (ConTec 4SCC). A four-bladed vane rotating coaxially was used for the impeller. The container of the rheometer had an internal diameter of $240 \mathrm{~mm}$ (9.44 in) and a depth of $240 \mathrm{~mm}$ (9.44 in), allowing a concrete sample volume of approximately $8 \mathrm{~L}$ $\left(0.28 \mathrm{ft}^{3}\right)$. Following the rheology tests, thixotropy and structural breakdown tests were performed.

\subsubsection{Evaluating torque plastic viscosity}

The testing procedure consisted of increasing the impeller speed, $N$, gradually to $0.7 \mathrm{rps}$ during $36 \mathrm{~s}$ subsequently reducing the speed stepwise to carry out the measurements of the torque, $T$, data. Each rotational velocity $(0.70,0.55,0.40,0.25$, and 0.10 rps) was maintained for $6 \mathrm{~s}$ to ensure breakdown of the structure. The torque-rotational velocity data in the descending curve were linear corresponding to a Bingham fluid, as follows: $T=g+h N$, where $g$ (in $\mathrm{N} \mathrm{mm}$ ) and $h$ (in $\mathrm{N} \mathrm{mm} \mathrm{s)} \mathrm{are} \mathrm{coefficients} \mathrm{for} \mathrm{apparent}$ yield stress and torque plastic viscosity, respectively. The linear fit always resulted in coefficient of correlation $\left(R^{2}\right)$ values greater than 0.92 .

\subsubsection{Evaluating thixotropy and structural breakdown}

Thixotropy and structural breakdown of the mixtures were evaluated by following three different ways. First method was the one recommended by Lapasin et al. [26]. In this method, 


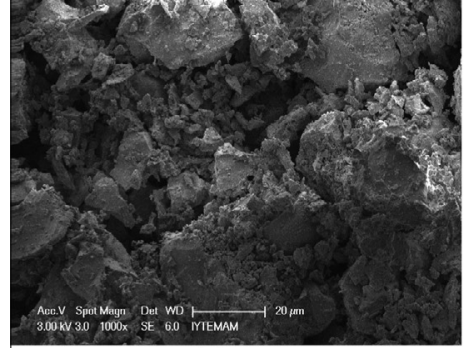

(a)

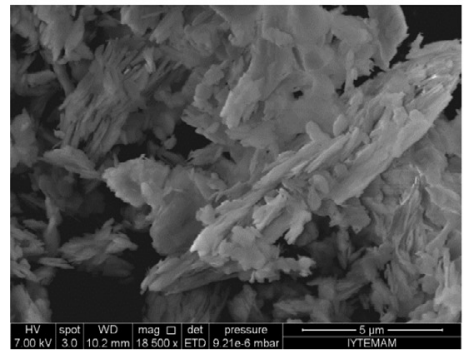

(d)

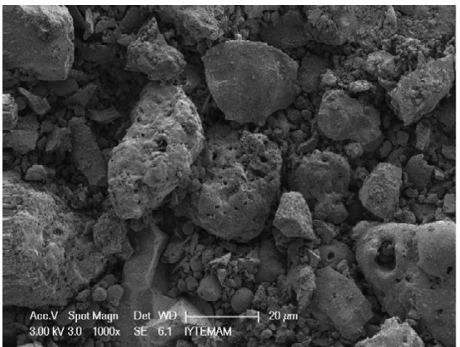

(b)

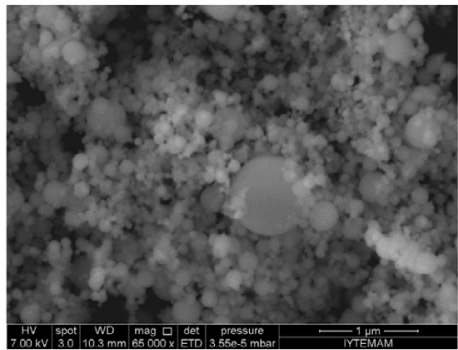

(e)

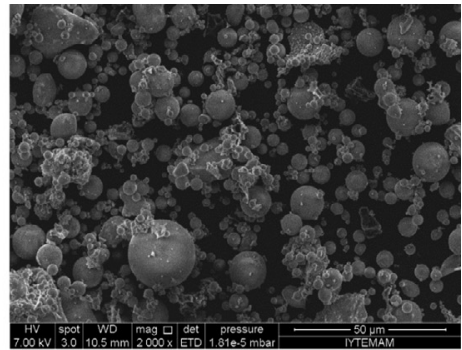

(c)

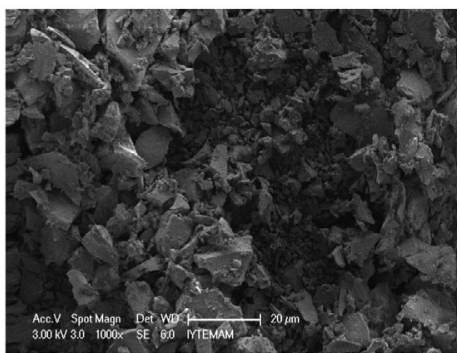

(f)

Fig. 2. SEM images of (a) PC, (b) FAC, (c) FAF, (d) MK, (e) SF and (f) BFS particles.

Table 2

Mix proportions of SCC mixtures having $\mathrm{w} / \mathrm{b}=0.44\left(\mathrm{~kg} / \mathrm{m}^{3}\right)$.

\begin{tabular}{|c|c|c|c|c|c|c|c|c|c|c|c|c|}
\hline \multirow[t]{2}{*}{ Mixture ID } & \multirow[t]{2}{*}{ Water } & \multirow[t]{2}{*}{ PC } & \multirow[t]{2}{*}{ SF } & \multirow[t]{2}{*}{ FAC } & \multirow[t]{2}{*}{ FAF } & \multirow[t]{2}{*}{ MK } & \multirow[t]{2}{*}{ BFS } & \multirow[t]{2}{*}{ VMA } & \multirow[t]{2}{*}{ HRWR } & \multicolumn{2}{|c|}{ Aggregates (SSD) } & \multirow[t]{2}{*}{$V_{\text {paste }}\left(\mathrm{L} / \mathrm{m}^{3}\right)$} \\
\hline & & & & & & & & & & Fine & Coarse & \\
\hline Control & 200 & 454.5 & - & - & - & - & - & - & 5.75 & 883 & 783 & 365.6 \\
\hline $4 S F$ & 200 & 436.5 & 18 & - & - & - & - & - & 6.7 & 880 & 778 & 368.6 \\
\hline $8 \mathrm{SF}$ & 200 & 418.5 & 36 & - & - & - & - & - & 7.5 & 875 & 774 & 371.5 \\
\hline $12 \mathrm{SF}$ & 200 & 400 & 54.5 & - & - & - & - & - & 8.0 & 870 & 771 & 374.1 \\
\hline 8SF18BFS & 200 & 337 & 36 & - & - & - & 81.5 & - & 6.7 & 874 & 774 & 372.1 \\
\hline $18 \mathrm{FAC}$ & 200 & 373 & - & 81.5 & - & - & - & - & 5.82 & 878 & 778 & 369.5 \\
\hline $36 \mathrm{FAC}$ & 200 & 291 & - & 163.5 & - & - & - & - & 6.35 & 872 & 773 & 373.8 \\
\hline 36FAC18BFS & 200 & 209.5 & - & 163.5 & - & - & 81.5 & - & 5.5 & 871 & 772 & 374.4 \\
\hline 18FAF & 200 & 373 & - & - & 81.5 & - & - & - & 4.67 & 872 & 772 & 372.8 \\
\hline $36 \mathrm{FAF}$ & 200 & 291 & - & - & 163.5 & - & - & - & 4.36 & 859 & 762 & 380.7 \\
\hline 36FAF18BFS & 200 & 209.5 & - & - & 163.5 & - & 81.5 & - & 4.31 & 858 & 761 & 382.0 \\
\hline $4 \mathrm{MK}$ & 200 & 436.5 & - & - & - & 18 & - & - & 6.18 & 881 & 781 & 367.3 \\
\hline 8MK & 200 & 418.5 & - & - & - & 36 & - & - & 6.5 & 878 & 779 & 368.9 \\
\hline $18 \mathrm{MK}$ & 200 & 373 & - & - & - & 81.5 & - & - & 7.5 & 873 & 773 & 373.2 \\
\hline $36 \mathrm{MK}$ & 200 & 291 & - & - & - & 163.5 & - & - & 10 & 861 & 762 & 381.7 \\
\hline 36MK18BFS & 200 & 209.5 & - & - & - & 163.5 & 81.5 & - & 9.35 & 860 & 761 & 382.5 \\
\hline $18 \mathrm{BFS}$ & 200 & 373 & - & - & - & - & 81.5 & - & 5.35 & 881 & 781 & 366.6 \\
\hline 8SF18FAC18BFS & 200 & 255.5 & 36 & 81.5 & - & - & 81.5 & - & 7.0 & 868 & 769 & 376.2 \\
\hline VMA & 200 & 454.5 & - & - & - & - & - & 4.6 & 8.0 & 883 & 783 & 367.7 \\
\hline
\end{tabular}

Notes: $1 \mathrm{~kg} / \mathrm{m}^{3}=1.68421 \mathrm{~b} / \mathrm{y} \mathrm{d}^{3}$

after five minutes of rest in the bowl of the rheometer, the mixture was subjected to a constant rotational speed of $0.2 \mathrm{rps}$ for $10 \mathrm{~s}$. Then, after another five-minute rest period, the mixture was subjected to a constant rotational speed of $0.4 \mathrm{rps}$ for 10 s. The same procedure was repeated for speeds of 0.6 and 0.8 rps. For each speed, the time-dependent change in torque was recorded, and then the initial torque $\left(T_{i}\right)$ and equilibrium torque $\left(T_{e}\right)$ values were determined (Fig. 3a). Then, initial torque values and equilibrium torque values were plotted on torque-rotational speed graphs (Fig. 3b). Second order polynomial functions were fitted to the data (Fig. $3 \mathrm{~b}$ ). The area between the initial torque curve and equilibrium curve, calculated by integration, was used to quantify the thixotropy and structural breakdown. This area is called "breakdown area" (Fig. 3b).

Second method was similar to the one recommended by Legrand [46]. In this calculation method, only a part of the data obtained for the breakdown area calculations were used. The difference between the initial torque $\left(T_{i}\right)$ and equilibrium torque $\left(T_{e}\right)$ values determined for $0.4 \mathrm{rps}$ was divided by the rotational speed $N=0.4$ rps. In other words, drop in apparent viscosity ( $\Delta_{\text {app }}$ was determined by $\Delta_{\text {app }}\left(T_{i}-T_{e} / N\right)$.

In the third method, after a rest period of $5 \mathrm{~min}$ in the rheometer bowl, a constant and very slow rotational speed of 0.03 rps was applied to the vane immersed in fresh concrete mixtures, and the resulting torque was measured as a function of time [27]. Torque-time graph shows a linear elastic region up to the yield torque value. Beyond this value, the bond is broken and the applied shear allows the flow of the material, therefore the torque value decreases. This yield (maximum) torque value $\left(\tau_{r 0}\right)$, is called as "yield value at rest". A typical torque-time graph (Fig. 4) for the determination of yield value at rest is illustrated for 36FAF mixture with $\mathrm{w} / \mathrm{b}$ ratio of 0.44 . 
Table 3

Mix proportions of SCC mixtures having $\mathrm{w} / \mathrm{b}=0.50\left(\mathrm{~kg} / \mathrm{m}^{3}\right)$.

\begin{tabular}{|c|c|c|c|c|c|c|c|c|c|c|c|c|}
\hline \multirow[t]{2}{*}{ Mixture ID } & \multirow[t]{2}{*}{ Water } & \multirow[t]{2}{*}{ PC } & \multirow[t]{2}{*}{$\mathrm{SF}$} & \multirow[t]{2}{*}{ FAC } & \multirow[t]{2}{*}{ FAF } & \multirow[t]{2}{*}{ MK } & \multirow[t]{2}{*}{ BFS } & \multirow[t]{2}{*}{ VMA } & \multirow[t]{2}{*}{ HRWR } & \multicolumn{2}{|c|}{ Aggregates (SSD) } & \multirow[t]{2}{*}{$V_{\text {paste }}\left(\mathrm{L} / \mathrm{m}^{3}\right)$} \\
\hline & & & & & & & & & & Fine & Coarse & \\
\hline Control & 200 & 400 & - & - & - & - & - & - & 4.5 & 908 & 805 & 347 \\
\hline $4 S F$ & 200 & 384 & 16 & - & - & - & - & - & 5.0 & 905 & 802 & 349.4 \\
\hline $8 \mathrm{SF}$ & 200 & 368 & 32 & - & - & - & - & - & 5.33 & 901 & 799 & 351.5 \\
\hline $12 \mathrm{SF}$ & 200 & 352 & 48 & - & - & - & - & - & 6.33 & 897 & 795 & 354.4 \\
\hline 8SF18BFS & 200 & 296 & 32 & - & - & - & 72 & - & 4.8 & 900 & 798 & 352.3 \\
\hline $18 \mathrm{FAC}$ & 200 & 328 & - & 72 & - & - & - & - & 4.6 & 905 & 801 & 350.5 \\
\hline $36 F A C$ & 200 & 256 & - & 144 & - & - & - & - & 5.05 & 900 & 797 & 354.3 \\
\hline 36FAC18BFS & 200 & 184 & - & 144 & - & - & 72 & - & 4.47 & 898 & 796 & 355 \\
\hline 18FAF & 200 & 328 & - & - & 72 & - & - & - & 4.0 & 899 & 796 & 353.8 \\
\hline $36 \mathrm{FAF}$ & 200 & 256 & - & - & 144 & - & - & - & 3.67 & 890 & 787 & 360.7 \\
\hline 36FAF18BFS & 200 & 184 & - & - & 144 & - & 72 & - & 3.65 & 889 & 786 & 361.9 \\
\hline $4 \mathrm{MK}$ & 200 & 384 & - & - & - & 16 & - & - & 4.85 & 906 & 803 & 348.5 \\
\hline $8 \mathrm{MK}$ & 200 & 368 & - & - & - & 32 & - & - & 5.1 & 904 & 801 & 350 \\
\hline $18 \mathrm{MK}$ & 200 & 328 & - & - & - & 72 & - & - & 6.0 & 899 & 797 & 353.8 \\
\hline $36 \mathrm{MK}$ & 200 & 256 & - & - & - & 144 & - & - & 8.0 & 889 & 788 & 361 \\
\hline 36MK18BFS & 200 & 184 & - & - & - & 144 & 72 & - & 7.45 & 888 & 787 & 361.7 \\
\hline 18BFS & 200 & 328 & - & - & - & - & 72 & - & 4.30 & 907 & 803 & 348 \\
\hline 8SF18FAC18BFS & 200 & 224 & 32 & 72 & - & - & 72 & - & 5.6 & 895 & 793 & 356.4 \\
\hline VMA & 200 & 400 & - & - & - & - & - & 4.6 & 6.0 & 908 & 805 & 348.4 \\
\hline
\end{tabular}

Notes: $1 \mathrm{~kg} / \mathrm{m}^{3}=1.68421 \mathrm{~b} / \mathrm{y} \mathrm{d}^{3}$.

Table 4

Mix proportions of SCC mixtures having $\mathrm{w} / \mathrm{b}=0.56\left(\mathrm{~kg} / \mathrm{m}^{3}\right)$.

\begin{tabular}{|c|c|c|c|c|c|c|c|c|c|c|c|c|}
\hline \multirow[t]{2}{*}{ Mixture ID } & \multirow[t]{2}{*}{ Water } & \multirow[t]{2}{*}{ PC } & \multirow[t]{2}{*}{ SF } & \multirow[t]{2}{*}{ FAC } & \multirow[t]{2}{*}{ FAF } & \multirow[t]{2}{*}{ MK } & \multirow[t]{2}{*}{ BFS } & \multirow[t]{2}{*}{ VMA } & \multirow[t]{2}{*}{ HRWR } & \multicolumn{2}{|c|}{ Aggregates (SSD) } & \multirow[t]{2}{*}{$V_{\text {paste }}\left(\mathrm{L} / \mathrm{m}^{3}\right)$} \\
\hline & & & & & & & & & & Fine & Coarse & \\
\hline Control & 200 & 357 & - & - & - & - & - & - & 3.9 & 929 & 822 & 332.7 \\
\hline $4 \mathrm{SF}$ & 200 & 342.7 & 14.2 & - & - & - & - & - & 4.2 & 925 & 820 & 334.6 \\
\hline $8 \mathrm{SF}$ & 200 & 328.5 & 28.5 & - & - & - & - & - & 4.53 & 922 & 818 & 336.6 \\
\hline $12 \mathrm{SF}$ & 200 & 314.5 & 42.5 & - & - & - & - & - & 5.66 & 918 & 815 & 339.3 \\
\hline 8SF18BFS & 200 & 264.5 & 28.5 & - & - & - & 64 & - & 4.5 & 921 & 816 & 337.7 \\
\hline $18 \mathrm{FAC}$ & 200 & 293 & - & 64 & - & - & - & - & 4.0 & 925 & 818 & 335.8 \\
\hline $36 F A C$ & 200 & 228.5 & - & 128.5 & - & - & - & - & 4.15 & 919 & 815 & 339.0 \\
\hline 36FAC18BFS & 200 & 164.5 & - & 128.5 & - & - & 64 & - & 4.0 & 918 & 814 & 340.0 \\
\hline 18FAF & 200 & 293 & - & - & 64 & - & - & - & 3.47 & 921 & 814 & 338.7 \\
\hline $36 \mathrm{FAF}$ & 200 & 228.5 & - & - & 128.5 & - & - & - & 3.23 & 911 & 807 & 345.0 \\
\hline 36FAF18BFS & 200 & 164.5 & - & - & 128.5 & - & 64 & - & 3.2 & 910 & 806 & 346.1 \\
\hline $4 \mathrm{MK}$ & 200 & 342.7 & - & - & - & 14.25 & - & - & 4.1 & 927 & 822 & 333.9 \\
\hline $8 \mathrm{MK}$ & 200 & 328.5 & - & - & - & 28.5 & - & - & 4.2 & 925 & 820 & 335.1 \\
\hline $18 \mathrm{MK}$ & 200 & 293 & - & - & - & 64 & - & - & 5.26 & 920 & 816 & 338.8 \\
\hline $36 \mathrm{MK}$ & 200 & 228.5 & - & - & - & 128.5 & - & - & 7.2 & 911 & 807 & 345.4 \\
\hline 36MK18BFS & 200 & 164.5 & - & - & - & 128.5 & 64 & - & 6.8 & 909 & 805 & 346.1 \\
\hline $18 \mathrm{BFS}$ & 200 & 293 & - & - & - & - & 64 & - & 3.65 & 928 & 820 & 333.6 \\
\hline 8SF18FAC18BFS & 200 & 200.5 & 28.5 & 64 & - & - & 64 & - & 4.87 & 917 & 812 & 341.0 \\
\hline VMA & 200 & 357 & - & - & - & - & - & 4.6 & 5.48 & 929 & 822 & 334.2 \\
\hline
\end{tabular}

Notes: $1 \mathrm{~kg} / \mathrm{m}^{3}=1.68421 \mathrm{~b} / \mathrm{y} \mathrm{d}^{3}$.

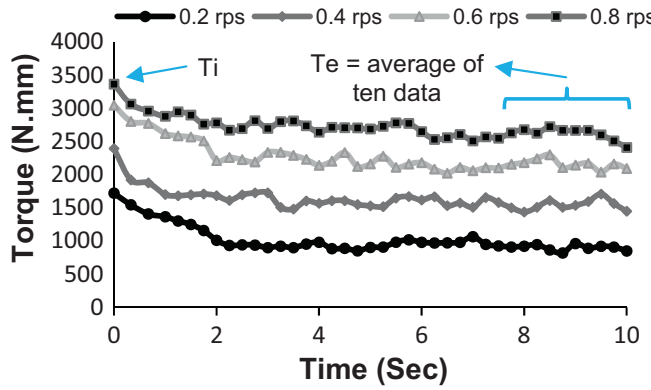

(a)

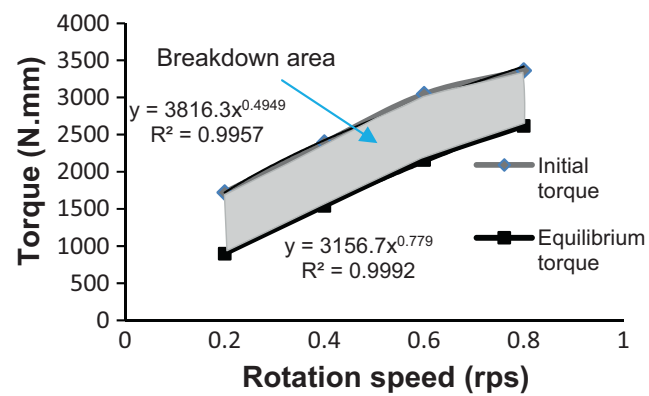

(b)

Fig. 3. Breakdown area method for the $36 \mathrm{FAF}$ mixture with $w / b=0.44$ (a) breakdown curves and (b) area calculation. 


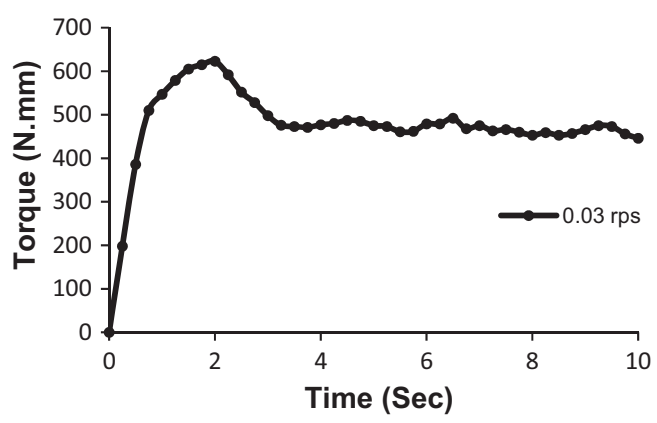

Fig. 4. Typical torque-time profile for the $36 F A F$ mixture with $w / b=0.44$.

\section{Results and discussion}

\subsection{HRWR demand}

The HRWR concentrations to produce a $650 \mathrm{~mm}$ (25.59 in) slump-flow diameter for each SCC mixture are illustrated in Fig. 5a-c. As can be seen in the left-hand side of the control mixtures, FAF and BFS decreased the HRWR requirement relative to the control mixture. In addition, replacement of PC by SF, MK and FAC increased the HRWR demand compared to that of the mixtures made with only PC. Incorporation of greater amounts of SF, MK and FAC present in binary, ternary, and quaternary cements necessitated greater HRWR demand, while the HRWR demand decreased as the FAF content increased.

Among the SCM having extremely high fineness (SF and MK), HRWR demand in the mixtures containing SF was more pronounced in comparison with MK. For example, HRWR demand was increased by approximately $40 \%$ when the percentage of SF was increased from $0 \%$ to $12 \%$ but the increase in HRWR demand was approximately $30 \%$ when the percentage of MK was changed from $0 \%$ to $18 \%$ for $\mathrm{w} / \mathrm{b}$ ratio of 0.44 . The greater HRWR demand of SF than that of MK was also noted in other investigations $[8,47]$.

The high HRWR demand of SF is probably due to extremely fine nature and high surface area of grain content (Fig. 2e) and in the case of MK it maybe owing to their regular structure, elongated shape and high surface area of MK particles (Fig. 2d).

All mixtures containing FAC required additional HRWR to secure the target slump flow value, as compared to the control mixtures. On the other hand, in all w/b ratios, FAF exhibited the lowest HRWR demand values in binary and ternary mixtures. This can be attributed to the irregular shape, cellular surface and high porosity of the FAC particles (Fig. 2b) and to the spherical morphology, smooth surface texture of the grains and low porosity of the FAF grains (Fig. 2c).

In all of the ternary mixtures that contain BFS, HRWR demand was lower when compared to the mixtures without BFS. This effect of BFS can be attributed to the morphology of glassy slag particles as well as their smooth surface, resulting in low adsorption potential (Fig. 2f).

Mixtures containing VMA required more HRWR when compared to the control mixtures. The above results are in agreement with other studies $[5,8,9,47]$.

The effect of $w / b$ ratio on the HRWR demand is shown in Fig. $5 d$. As expected, HRWR contents increased as the w/b decreased. It is also possible to conclude that the trend of HRWR demand was similar for all $\mathrm{w} / \mathrm{b}$. In other words, the variation of HRWR demand with the binder system followed the same behavior regardless of the $\mathrm{w} / \mathrm{b}$ ratio.

\subsection{Torque plastic viscosity}

The torque plastic viscosity $(h)$ results of the mixtures are given in Fig. 6a-c. As demonstrated in these figures for all $w / b$ ratios, the partial replacement of PC by FAC, FAF and MK increased the $h$ values of the mixtures (see the mixtures at the right-hand side of the

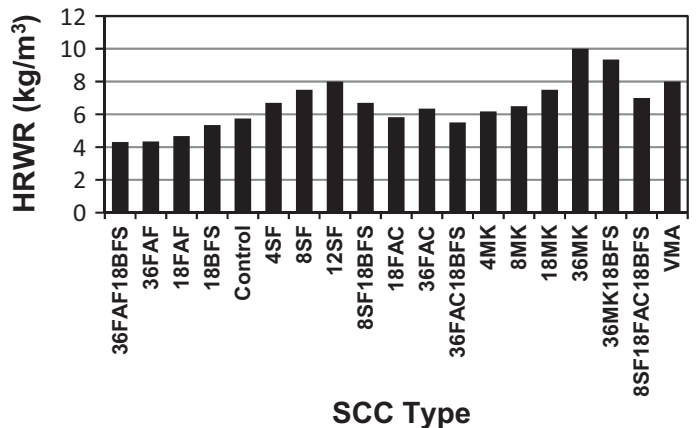

(a) $w / b=0.44$

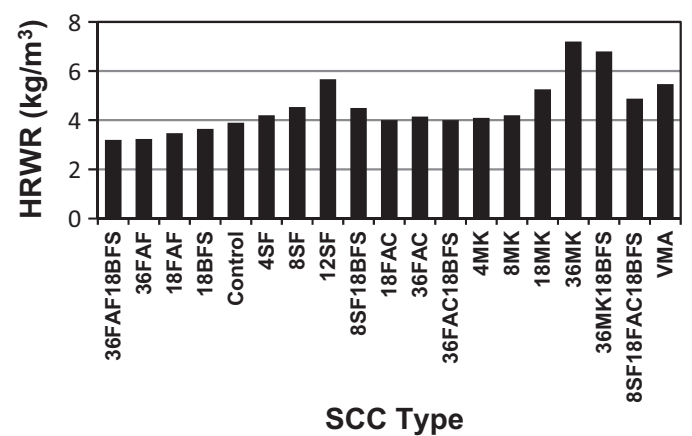

(c) $w / b=0.56$

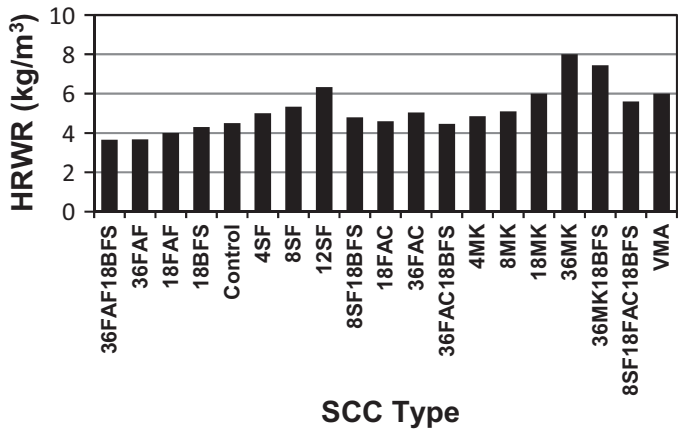

(b) $\mathrm{w} / \mathrm{b}=0.50$

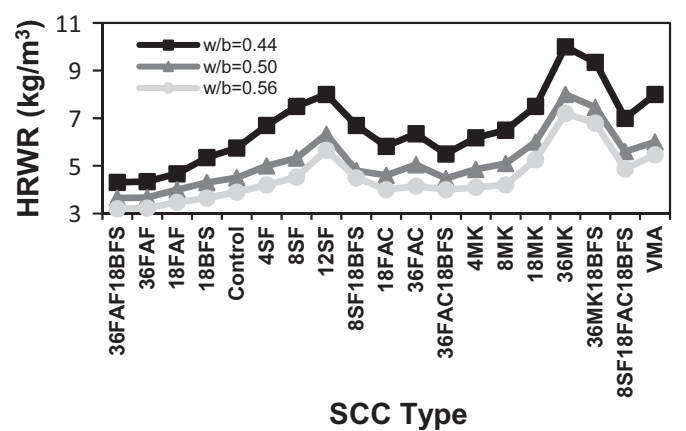

(d) different $\mathrm{w} / \mathrm{b}$

Fig. 5. HRWR demand of the mixtures with (a) $w / b=0.44$, (b) $w / b=0.50$, (c) $w / b=0.56$ and (d) different $w / b$. 


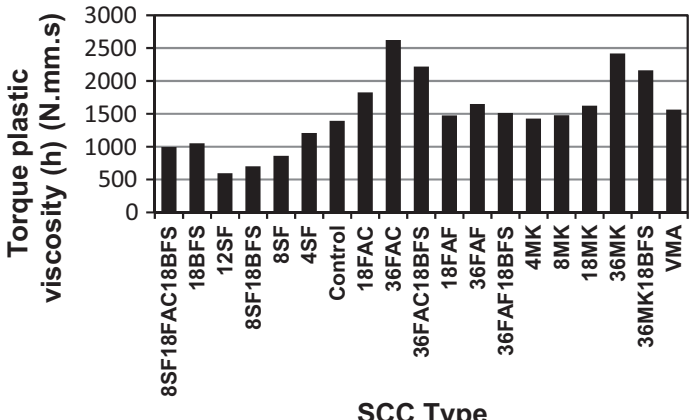

(a) $w / b=0.44$

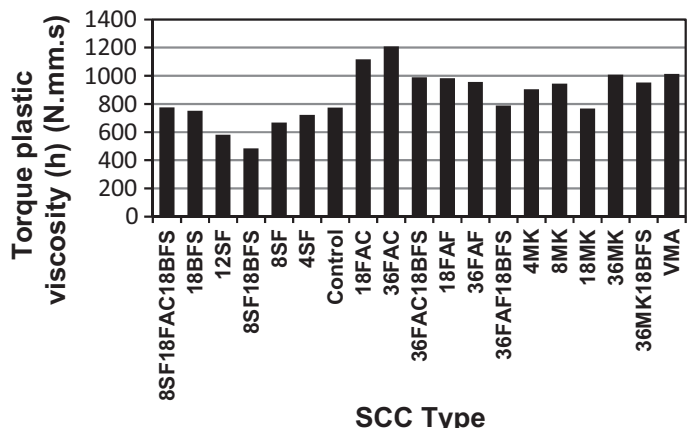

(c) $\mathrm{w} / \mathrm{b}=0.56$

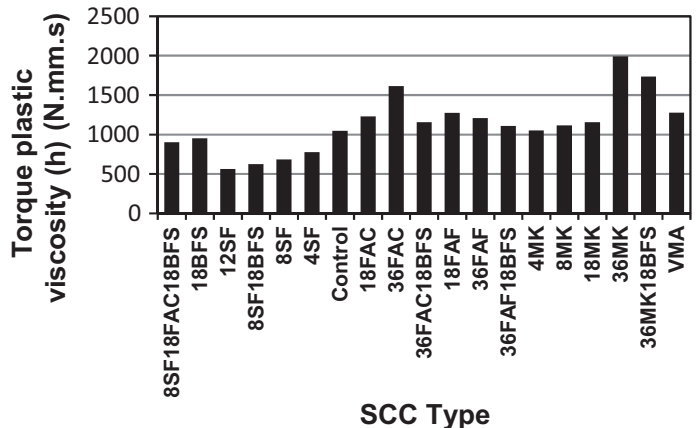

(b) $\mathrm{w} / \mathrm{b}=0.50$

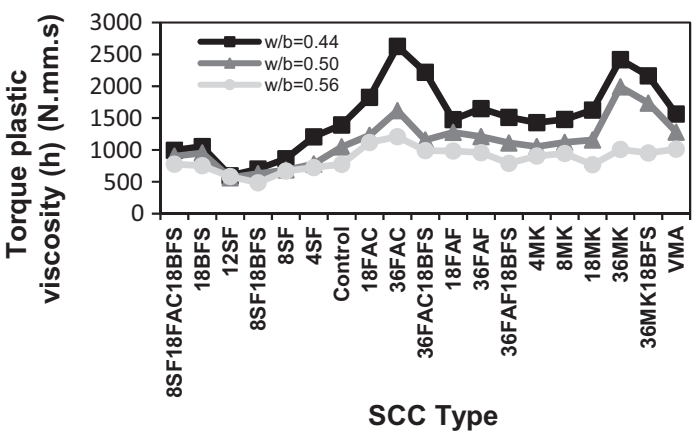

(d) different $\mathrm{w} / \mathrm{b}$

Fig. 6. Torque plastic viscosity of the mixtures with (a) $w / b=0.44$, (b) $w / b=0.50$, (c) $w / b=0.56$ and (d) different $w / b$.

control mixtures in these figures). 36MK mixture with w/b ratio of 0.50 , whose plastic viscosity was approximately $90 \%$ greater than that of the control mixture, showed the highest increase in plastic viscosity.

On the other hand, incorporation of SF and BFS reduced the $h$ values in all w/b ratios (Fig. 6a-c). $12 \%$ replacement with SF in the mixture with $0.44 \mathrm{w} / \mathrm{b}$ ratio resulted in the greatest reduction (approximately 2.3 times less) in $h$. The amount of reduction was less as the percentage of SF was decreased. This behavior was contrary to the behaviors of MK and FAC: as replacement level of MK and FAC was increased, $h$ values also increased. Meanwhile, except for the mixture with $\mathrm{w} / \mathrm{b}$ ratio of 0.44 , negligible reduction in $h$ was observed when amount of FAF was increased. Similar results were reported by the other investigations for MK bearing mixtures [8]. However, the data related with the effect SF on the plastic viscosity of SCC is contradictory. Some of the researchers found that SF reduces the plastic viscosity (similar to the finding of this study) but the others reported that SF has not a significant effect on the viscosity of SCC $[5,8]$.

The decrease in torque plastic viscosity due to the presence of SF in the SCC mixture was attributed to the following facts: The sphericity of SF particles provides better packing than PC particles resulting in lower shear stress and lower plastic viscosity values $[21,48]$. Another reason for reduction of $h$ with increasing percentage of SF can be related to the difference in the volume of the binders. Owing to the difference between the specific gravity of PC and $\mathrm{SF}$, mixtures containing SF had greater binder volumes causing reduction in $h$.

MK particles, owing to their high porosity, can absorb water and HRWR, leading to a reduction in inter-particle distance between solid particles and an increase in the level of attractive forces within solid particles that can be significant sake for obtaining high $h$ values. Moreover, MK particles have elongated shape and irregular surface texture (Fig. 2d), and contrary to the lubrication effect of spherical shape and smooth surface (as was the case in SF), they can reduce workability of SCC mixtures thereby increase the $h$ values. Cassagnabere et al. [49] reported that in addition to high open porosity at the surface, elongated shape, irregular surface texture, least rounded and most rugged MK particles reduce workability and flowability of the mixtures.

In all $w / b$ ratios, the mixtures containing FAC showed higher torque plastic viscosity in comparison with FAF ones. FAF particles, owing to their spherical shapes (Fig. 2c) which typically pack better than irregularly-shaped FAC particles, can lead to a higher ballbearing effect to reduce interparticle friction, thereby enhancing workability and reduction in $h$.

As shown in Fig. 6a-c lower $h$ values were obtained in the quaternary system (8SF18FAC18BFS) in comparison with control mixtures and 18FAC mixture in all $\mathrm{w} / \mathrm{b}$ ratios. In addition, utilization of $18 \%$ BFS with other SCM in ternary systems resulted in a considerable decrease in $\mathrm{h}$ values compared to those of binary systems without BFS. The same result was also obtained by Boukendakdji et al. [9]. They noted that the SCC mixtures incorporating BFS exhibited lower plastic viscosity than the reference mixture containing only PC. Moreover, the decrease in h was more pronounced when BFS content was increased.

The reason of this kind of treatment can be related to the degree of hydration of these mixtures. In quaternary mixtures, SCM replaced approximately $44 \%$ of PC by mass. Solid volume concentration obtained from hydration of PC and magnitude of restructuring and strength of inter-particle links which have significant effect in plastic viscosity values will be less in quaternary systems owing to the lower reactivity of SCM than PC. Moreover, in the quaternary system, PC is replaced with three types of finer SCM (SF, FAC and $\mathrm{BFS}$ ). The fine particles of these SCM can fill the spaces between PC particles. Similarly, SF can take place between FAC and BFS 
particles, resulting in higher ball-bearing effect. This can help reducing the friction between cementitious materials and decrease the plastic viscosity of quaternary systems [50]. Another reason for the lower viscosity of quaternary mixtures is their higher paste volumes [21] (For example, paste volumes of quaternary and control mixtures with $\mathrm{w} / \mathrm{b}=0.44$ are 376.2 and $365.5 \mathrm{~L} / \mathrm{m}^{3}$, respectively, as can be seen form Table 3 ).

The torque plastic viscosity of VMA mixtures was higher than that of control mixtures, as expected. In this study, it was aimed to see whether VMA can be an alternative material to SCM in adjusting the plastic viscosity, which is necessary for stability of SCC. The results showed that VMA resulted in comparable $h$ values and HRWR demand with SCM.

In all SCC mixtures, amount of water was kept constant and different $w / b$ values were achieved by varying the binder content (Tables 2-4). Accordingly, the relative content of aggregate increased with the reduction in binder content as $w / b$ ratio was increased. For example, when the control mixture is considered, aggregate volume (1000 L minus P.V. in Tables 2-4) was $634.4 \mathrm{~L}$, $653 \mathrm{~L}$ and $667.3 \mathrm{~L}$ for $\mathrm{w} / \mathrm{b}$ ratios $0.44,0.50$ and 0.56 , respectively. In other words, aggregate volume increased by $5.19 \%$ when the $\mathrm{w} / \mathrm{b}$ ratio was increased to 0.56 from 0.44 . Binder content, aggregate content and $\mathrm{w} / \mathrm{b}$ are among the most important factors affecting plastic viscosity of SCC mixtures. Higher degree of internal friction and resistance to flow thereby greater plastic viscosity is an expected phenomenon in SCC mixtures with high concentration of aggregate for a constant $\mathrm{w} / \mathrm{b}$ ratio. On the other hand, higher degree of cohesiveness and progressive tendency to formation of a gel structure therefore greater amount of plastic viscosity in rich mixtures is reported by several authors [5,37,38,51]. As summarized in Fig. 6d, in spite of the high aggregate concentration in high $\mathrm{w} / \mathrm{b}$ ratios mixtures, $h$ values decreased as $\mathrm{w} / \mathrm{b}$ ratio was increased. This kind of behavior proposes the importance of $w / b$ ratio in SCC mixtures. Increase in the paste fluidity due to higher $\mathrm{w} / \mathrm{b}$ ratio resulted in a decrease in plastic viscosity of SCC.

\subsection{Thixotropy and structural breakdown}

\subsubsection{Breakdown area values}

The breakdown area values for binary, ternary and quaternary mixtures containing SCM or VMA are given in Fig. 7a-c. As illustrated in these figures, greater values were obtained for SCC mixtures made with SF, FAC, FAF and MK when compared to that of the control mixtures. The increase was more significant as percentage of FAC, FAF and MK replacements were increased. The highest value, which was approximately 2.2 times greater than that of the control mixture, was observed in $36 \mathrm{MK}$ mixture with $\mathrm{w} / \mathrm{b}$ ratio of 0.44 .

Breakdown area calculations strongly depend on the factors that affect initial shear stress and equilibrium shear stress values determined during the tests [26]. As cited by Assaad et al. [5,40], Struble [52] suggested that particle packing and interparticle links responsible for flocculation are important factors that affect thixotropy in cement based system. It was reported that incorporation of SCM with higher surface area increases the number of inter-particle links and the level of attractive forces within solid particles, leading to higher initial shear stress values (upward shift of initial torque, $T_{i}$ curve in Fig. $3 \mathrm{~b}$ ). As long as the concrete is left at rest, the structural build-up becomes more significant, thus requiring higher initial shear stress $\left(T_{i}\right)$ to break down the structure coming to the equilibrium shear stress. Tattersall et al. [21] concluded that in cement based systems, SCM with high packing density can reduce the equilibrium shear stress values by filling the voids and providing additional lubricant around aggregate particles (downward shift of equilibrium torque, $T_{e}$, values in Fig. $3 \mathrm{~b}$ ). Meanwhile, substitution of PC with SCM in cement based system

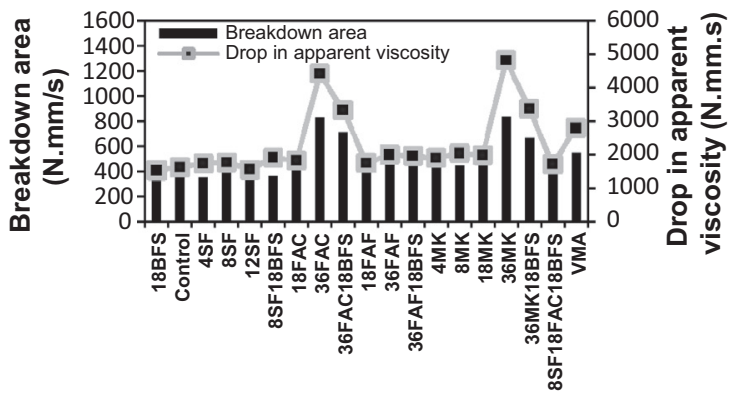

ScC Type

(a) $w / b=0.44$

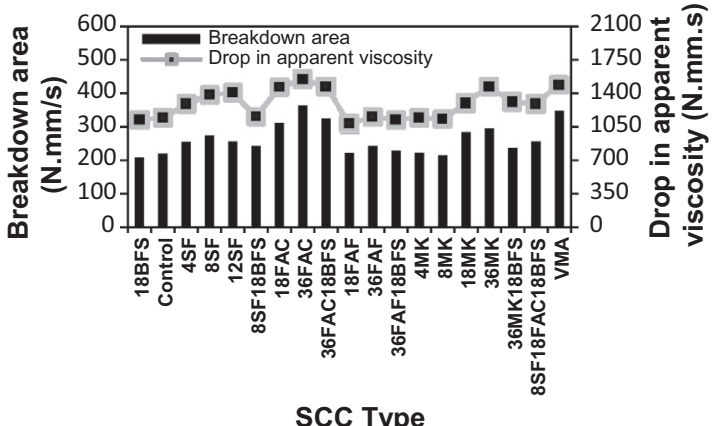

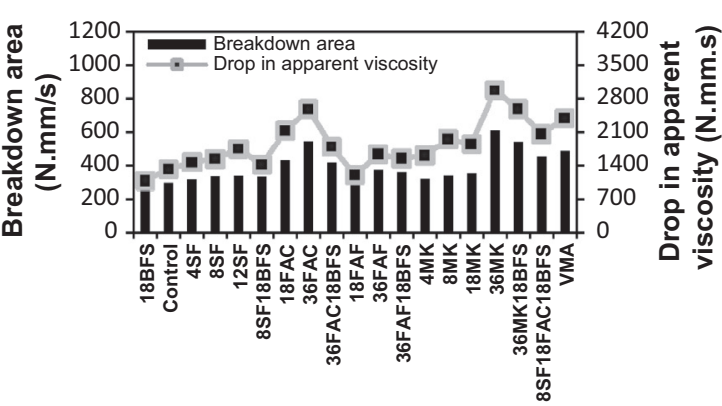

SCC Type

(b) $w / b=0.50$

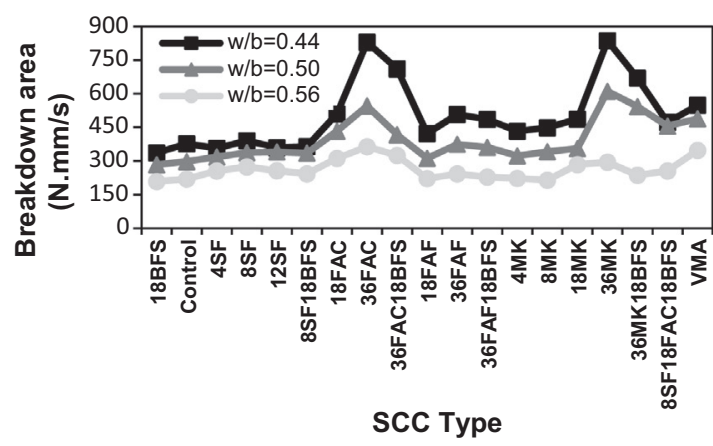

(d) different $\mathrm{w} / \mathrm{b}$

Fig. 7. Variation of structural breakdown area and drop in apparent viscosity for (a) $w / b=0.44$, (b) $w / b=0.50$, (c) $w / b=0.56$ and (d) different $w / b$. 
increases binder volume owing to the difference between the specific gravity of these materials, and therefore some decrease in equilibrium shear stress values can be expected [5]. When a concrete mixture which was left at rest for a sufficient time is sheared the particle spatial distribution and alignment become parallel to the flow direction, and the number of entanglements or associations decreases to a minimum, resulting in similar values of shear stress at equilibrium $\left(T_{e}\right)$ during shearing $[5,53]$.

4.3.1.1. MK. Higher breakdown area values of the mixtures containing MK can be related to difference in the volume of the binders. Owing to the difference between the specific gravity of cement and $\mathrm{MK}$, mixtures containing $\mathrm{MK}$ had greater binder volumes. For example, for $\mathrm{w} / \mathrm{b}$ ratio of 0.44 , paste volume of the control mixture was $365.6 \mathrm{~L}$ while that of the MK mixtures ranged between $367.3 \mathrm{~L}$ and $381.7 \mathrm{~L}$, corresponding to an increase of $0.46 \%$ and $4.4 \%$ respectively. The increases in the paste volume were almost the same also for other $\mathrm{w} / \mathrm{b}$ ratios. Higher paste volumes caused reductions in equilibrium torque values. Another reason for increase in thixotropy and structural breakdown values with higher percentage of MK can be attributed to the higher surface area and particle shape of MK particles: MK particles have higher surface area (Table 1), increasing the number of inter-particle links and the level of attractive forces within solid particles, and they have elongated shape (Fig. 2d), increasing the internal friction. Therefore, they can increase initial torque values.

4.3.1.2. FAC. Greater breakdown area values obtained for FAC mixtures in comparison with the control mixture containing only PC can be related to porous nature of the former binder. FAC particles, owing to their high porosity (Fig. 2b), can absorb water and HRWR. Hence, internal friction between solid particles can increase. As a result, coagulation of the system is increased and this can increase a higher initial torque values.

4.3.1.3. $S F$ and $F A F$. In the case of mixtures containing SF, except some irregularity in mixtures having $\mathrm{w} / \mathrm{b}$ ratio of 0.44 , breakdown area values were also increased. Since spherical particles can be assumed to pack better than angular ones, like those of PC [48], higher packing density of the mixtures containing FAF and SF, which have spherical particles (Fig. $2 \mathrm{c}$ and e), can reduce the equilibrium torque values. In addition, higher binder volume of the mixtures with SF and FAF and high surface area of SF particles can reduce the equilibrium torque values and increase initial torque values.

4.3.1.4. BFS. As plotted in Fig. $7 \mathrm{a}-\mathrm{c}$, for all $\mathrm{w} / \mathrm{b}$ ratios, breakdown area values were negligibly reduced when BFS were incorporated in the binary system. $18 \%$ replacement of BFS in the mixture with $0.44 \mathrm{w} / \mathrm{b}$ ratio caused in the greatest reduction (approximately $10 \%$ ) in the results. Besides, in all ternary systems, use of $18 \%$ BFS with other SCM resulted in a considerable decrease in the breakdown area values compared to those of binary systems without BFS. The BFS particles have a high specific surface area (Table 1) and smooth surface (Fig. 2f). Moreover, they have lower hydration reaction ability than PC. Also, BFS particles can fill into the spaces between larger particles of PC and lead to a decrease in frictional forces in BFS blended mixtures [47,54]. Due to these factors, replacement of PC with BFS resulted in a decrease initial torque values.

4.3.1.5. Quaternary blend. As shown in Fig. 7a-c, combination of several SCM types in the quaternary system ( $8 \%$ SF, $18 \%$ FAC, $18 \%$ $\mathrm{BFS}$ ) led to an increase in breakdown area values relative to the control mixture in all $\mathrm{w} / \mathrm{b}$ ratios. The results of the quaternary system showed that the effect of SF (increase in initial torques and decrease in equilibrium torques) and FAC (increase in initial torques) on increasing the breakdown area values was dominated to the effect of BFS (decrease in initial torques).

4.3.1.6. VMA. As seen in Fig. 7a-c, the breakdown area values of VMA mixtures were higher than that of control mixtures. Assad [5] reported that tending of water to be physically adsorbed by hydrogen and ionic bonding to the long chain polymers of the VMA is an important factor that affects the degree of thixotropy in fresh concrete. Besides, these molecules may develop attractive forces among each other, to form a gel and inter-particle links causing higher cohesiveness, thereby, greater degree of thixotropy. Depending on the VMA dosage, its effect on SCC rheology can be altered. In this study, only a single dosage of VMA which lies between the ranges recommended by the manufacturer was used. For the dosage value used in this study VMA resulted in comparable thixotropy values with other SCM.

4.3.1.7. $W / b$. As mentioned earlier, in all SCC mixtures, amount of water was kept constant and different $\mathrm{w} / \mathrm{b}$ values were achieved by varying the binder content. Hence, the relative content of aggregate increased with the reduction in binder content as $\mathrm{w} / \mathrm{b}$ ratio was increased (As can be seen in Table 2, the binder content and aggregate content of the control mixture with $w / b=0.44$ was $365.6 \mathrm{~L} / \mathrm{m}^{3}$ and $634.4 \mathrm{~L} / \mathrm{m}^{3}$ respectively. However, when the $\mathrm{w} / \mathrm{b}$ was increased to 0.56 (Table 4), the binder content decreased to $332.7 \mathrm{~L} / \mathrm{m}^{3}$ and the aggregate content increased to $667.3 \mathrm{~L} / \mathrm{m}^{3}$ ).

It is well known that the binder and aggregate contents and $\mathrm{w} / \mathrm{b}$ ratio are among the important factors affecting the degree of thixotropy and structural breakdown of SCC mixtures. The increase in aggregate concentration can lead to higher degree of internal friction and produce greater collision and resistance to flow, thereby resulting in greater initial shear stress values. On the other hand, for constant water contents, after a given period of rest, individual binder particles begin to flocculate and develop internal network in mixtures with higher binder contents. This leads to higher degree of cohesiveness, progressive tendency to formation of a gel structure and inter-particle links and developing internal networks. Therefore, greater initial shear stress values are expected in rich mixtures [5,51]. As shown in Fig. $7 d$, breakdown area values decreased as w/b ratio was increased. From these results it can be emphasized that among the two opposite effects (high aggregate content and low binder content) on the degree of thixotropy and structural breakdown, the effect of reduction in binder content (or increase in $\mathrm{w} / \mathrm{b}$ ratio) dominated the effect of increase in aggregate content.

Finally, it should be emphasized that the trend of change of breakdown area values with binder system was similar irrespective of $w / b$ ratio of the mixtures (Fig. $7 d$ ).

\subsubsection{Drop in apparent viscosity values}

As noted earlier, drop in apparent viscosity is an approach to assess the amplitude of the time-dependent phenomenon. The drop in apparent viscosity for 57 SCC mixtures with three different $\mathrm{w} / \mathrm{b}$ ratios are presented in Fig. $7 \mathrm{a}-\mathrm{c}$. It is possible to conclude that for a given $w / b$, the change of drop in apparent viscosity values with binder system is similar to the change of breakdown area values as can be seen from any of Fig. 7a-c. Therefore, similar discussions made for the breakdown area values can also be made for drop in apparent viscosity values.

The relationships between the structural breakdown area and $\Delta_{\text {app }}$ values determined at $0.4 \mathrm{rps}$ for all SCC mixtures having different $w / b$ ratios are plotted in Fig. $8 a-c$. From these figures, it can be concluded that good correlations with moderately high coefficient of correlation $\left(R^{2}\right)$ values ranging between 0.83 and 0.91 were observed. This shows that both the structural 


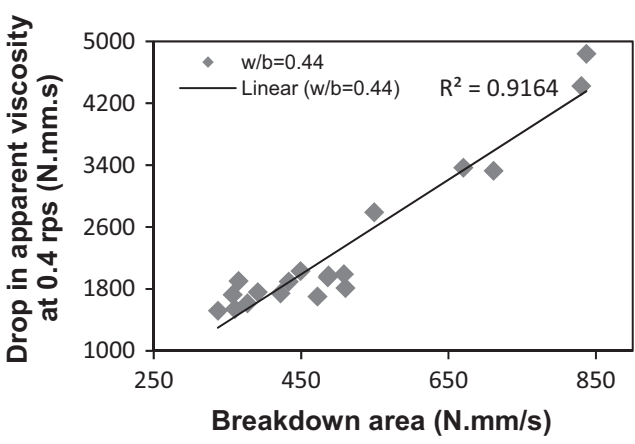

(a)

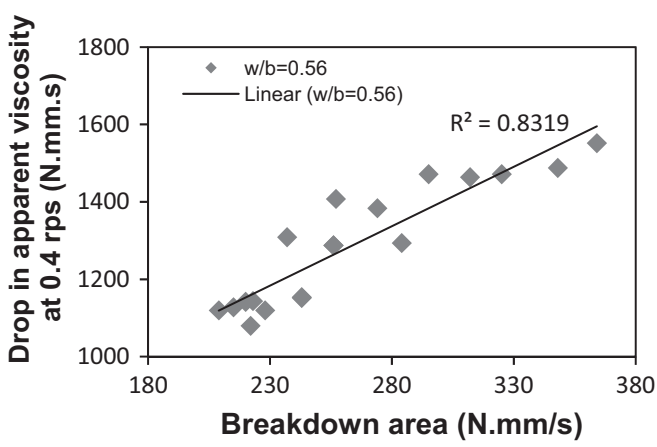

(c)

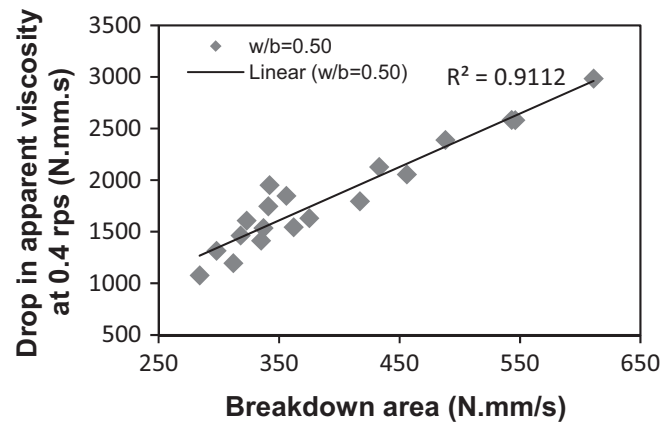

(b)

Fig. 8. Relationship between the structural breakdown area and $\Delta_{\text {app }}$ values determined at $0.4 \mathrm{rps}$ for $(\mathrm{a}) \mathrm{w} / \mathrm{b}=0.44,(\mathrm{~b}) \mathrm{w} / \mathrm{b}=0.50$, and $(\mathrm{c}) \mathrm{w} / \mathrm{b}=0.56$.

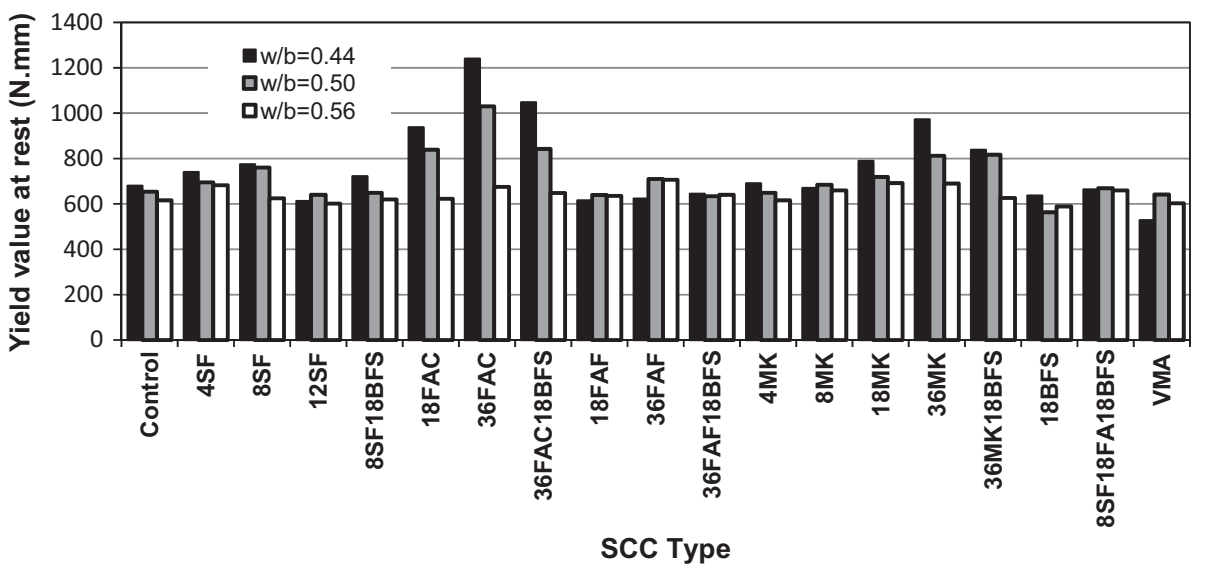

Fig. 9. Variation of at rest yield values for different w/b.

breakdown area method determined using four rotational speeds or the drop in apparent viscosity at a given rotational speed can be used to determine thixotropy and structural breakdown of SCC mixtures. However it should be noted that the breakdown area can be more exact in evaluating thixotropy as it employs four measurements, reducing the error in determining thixotropy and structural breakdown [2].

\subsubsection{Yield value at rest}

Yield value at rest indicates the coagulation state of the material that enables it to re-gain its shear strength when left at rest [5]. In this test, the interparticle links and attractive forces formed during the rest period are broken under very low shear rates. After elastic deformations, the bonds are broken upon reaching a critical stress (static yield stress), which is analogous to yielding behavior of steel under tension. The bond strength (yield value at rest) depends on the initial structuring in the fresh concrete and the discussions made above on the increase in the initial torque values also hold true for yield values at rest: Increase in the number of interparticle links and level of attractive forces affect the yield values at rest. The properties of SCM that affect these factors include the water and HRWR absorption characteristics, fineness and shape of the particles.

The yield values at rest of the SCC mixtures containing different binder systems are given in Fig. 9. However, as can be seen from this figure, the results did not vary significantly even for different $\mathrm{w} / \mathrm{b}$ ratios. Therefore, the differences between the mixtures were not clearly observable. Nevertheless, the mixtures with FAC had obviously higher values than the other mixtures especially at lower $\mathrm{w} / \mathrm{b}$ ratios. This result is consistent with those determined by the breakdown area and drop in apparent viscosity methods. 
The correlation between the breakdown area and yield value at rest results was also investigated. The coefficient of correlation $\left(R^{2}\right)$ was $0.58,0.46$ and 0.04 for mixtures having $\mathrm{w} / \mathrm{b}$ ratios of $0.44,0.50$ and 0.56 , respectively. The obtained results showed that there are not significant relations between the breakdown area values and yield values. Similar to the observations made in Fig. $8, R^{2}$ increased as $\mathrm{w} / \mathrm{b}$ ratio decreased. In other words, the thixotropy and structural breakdown data obtained by different methods get more consistent for lower $\mathrm{w} / \mathrm{b}$ ratios. It can also be noted that the drop in viscosity and breakdown area correlations are better than yield value at rest and breakdown area correlations.

\section{Conclusions}

The main conclusions derived from this study can be summarized as follows:

1. For the same slump flow values, FAF and BFS decreased the HRWR requirement relative to the control mixture. In addition, replacement of PC by SF, MK and FAC increased the HRWR demand compared to the mixtures made with only PC. Incorporation of greater amounts of SF, MK and FAC necessitated greater HRWR than control mixtures.

2. The partial replacement of PC by FAC, FAF and MK increased the plastic viscosity of the mixtures, regardless of the $\mathrm{w} / \mathrm{b}$ ratio. The highest increase (90\%) in plastic viscosity was observed in $36 \%$ MK mixture with $\mathrm{w} / \mathrm{b}$ ratio of 0.50 . As the percentage of MK and FAC was increased, plastic viscosity was also increased.

3. Incorporation of SF and BFS reduced the plastic viscosity values in all $\mathrm{w} / \mathrm{b}$ ratios. $12 \%$ replacement with $\mathrm{SF}$ in the mixture with $0.44 \mathrm{w} / \mathrm{b}$ ratio resulted in the greatest reduction (approximately 2.3 times less) in plastic viscosity.

4. Breakdown area of the mixtures containing SF, FAC, FAF, MK and VMA was higher than that of the control mixtures, regardless of the $\mathrm{w} / \mathrm{b}$ ratio. The highest increase (2.2 times greater) was observed in $36 \% \mathrm{MK}$ mixture with $\mathrm{w} / \mathrm{b}$ ratio of 0.44 . The amount of enhancement was stronger as percentage of substitution of FAC, FAF and MK were increased.

5. Breakdown area values were negligibly reduced when BFS were incorporated in the binary system. $18 \%$ replacement of BFS in the mixture having $\mathrm{w} / \mathrm{b}$ ratio of 0.44 reduced the result approximately by $10 \%$.

6. The quaternary system containing $8 \%$ SF, $18 \%$ FAC and $18 \%$ BFS led to an increase in breakdown area relative to the mixture containing only PC. Also in all ternary systems, use of $18 \%$ BFS with other SCM resulted in a considerable decrease in breakdown area compared to those of binary systems without BFS.

7. Thixotropy and structural breakdown was reduced as w/b ratio was increased. Since the water content of the mixtures was kept constant, any increase in $\mathrm{w} / \mathrm{b}$ ratio caused reduction in binder content and consequent increase in aggregate content. Among these two factors having opposite effects on the thixotropy and structural breakdown, the former one dominated over the latter. The trend of change of structural breakdown area with binder system was similar for different $\mathrm{w} / \mathrm{b}$ ratios.

8. Good correlations were established between structural breakdown area and drop in apparent viscosity values for each $\mathrm{w} / \mathrm{b}$. Hence, both the structural breakdown area method and the drop in apparent viscosity method can be used to determine thixotropy and structural breakdown values of SCC mixtures.

9. Comparison of the breakdown area and at rest yield values showed that there are not statistically clear relations between these approaches. Nevertheless, the different methods to evaluate the thixotropy and structural breakdown get more consistent when $\mathrm{w} / \mathrm{b}$ ratio of the mixtures gets smaller.

\section{Acknowledgments}

This paper is a part of a more extensive study supported by TUBITAK (The Scientific and Technological Research Council of Turkey) under the grant of 112M581. The authors would like to acknowledge this support.

\section{References}

[1] Mehta PK. Role of pozzolanic and cementitious material in sustainable development of the concrete industry. Fly ash, silica fume, slab, and natural pozzolans in concrete. In: Malhotra VM, editor. Proceedings of the sixth CANMENT/ACI/JCI international conference, SP-178, V. 1. American Concrete Institute, Farmington Hills, MI; 1998. p. 1-20.

[2] Assaad J, Khayat KH. Assessment of thixotropy of self-consolidating concrete and concrete-equivalent-mortar-effect of binder composition and content. ACI Mater J 2004;101:400-8.

[3] Guneyisi E, Gesoglu M, Ozbay E. Permeation properties of self-consolidating concretes with mineral admixtures. ACI Mater J 2011;108:150-8.

[4] Hassan AA, Lachemi M, Hossain K. Effect of metakaolin and silica fume on the durability of self-consolidating concrete. Cem Concr Compos 2012;34:801-7.

[5] Assaad J. Formwork pressure of self-consolidating concrete influence of thixotropy. PhD Thesis, University of Sherbrooke, Canada, 2004.

[6] Habert G, Roussel N. Study of two concrete mix-design strategies to reach carbon mitigation objectives. Cem Concr Compos 2009;31. p. 397-02.

[7] Uysal M, Akyuncu V. Durability performance of concrete incorporating class $f$ and class c fly ashes. Constr Build Mater 2012;34:170-8.

[8] Hassan A, Lachemi M, Hossain K. Effect of metakaolin and silica fume on rheology of self-consolidating concrete. ACI Mater J 2012;109:657-64.

[9] Boukendakdji O, Kadri EH, Kenai S. Effects of granulated blast furnace slag and superplasticizer type on the fresh properties and compressive strength of selfcompacting concrete. Cem Concr Compos 2012;34:583-90.

[10] Saleh Ahari R. Effect of mineral admixtures on rheological, thixotropic and permeability characteristics of self-consolidating concrete (SCC). PhD Thesis, Ege University, İzmir; 2014. p. 215 [in Turkish].

[11] Jau WC, Yang CT. Development of a modified concrete rheometer to measure the rheological behaviour of conventional and self-consolidating concretes. Cem Concr Compos 2010;32:450-60.

[12] Sahmaran M, Yaman IO, Tokyay M. Transport and mechanical properties of self consolidating concrete with high volume fly ash. Cem Concr Compos 2009;31:99-106.

[13] Khayat K, Yahia A, Sayed M. Effect of supplementary cementitious materials on rheological properties, bleeding, and strength of structural grout. ACI Mater J 2008;105(6):585-93.

[14] Roussel N. A thixotropy model for fresh fluid concretes: theory, validation and applications. Cem Concr Res 2006;36. p. 1797-06.

[15] Roussel N, Cussigh F. Distinct-layer casting of SCC: the mechanical consequences of thixotropy. Cem Concr Res 2008;38:624-32.

[16] Rahman MK, Baluch MH, Malik MA. Thixotropic behavior of self compacting concrete with different mineral admixtures. Constr Build Mater 2014;50:710-7.

[17] Barnes HA, Hutton JF, Walters K. An introduction to rheology. Amsterdam: Elsevier; 1989. p. 199.

[18] Wallevik JE. Thixotropic investigation on cement paste: experimental and numerical approach. J Non-Newtonian Fluid Mech 2005;132:86-99.

[19] Wallevik JE. Rheology of particle suspensions-fresh concrete, mortar and cement paste with various types of lignosulfonates, $\mathrm{PhD}$ Thesis, The Norwegian University of Science and Technology, Trondheim; 2003.

[20] Hattori K, Izumi K. Rheology of fresh cement and concrete, in: P.F.G. Banfill editor. Rheology of fresh cement and concrete, Proc. of the international conference organized by The British society of rheology, University of Liverpool, March 1990, E \& FN Spon, London; 1991. p. 83-92.

[21] Tattersall GH, Banfill PFG. The rheology of fresh concrete. London: Pitman Advanced Publishing Program; 1983.

[22] Hunter RJ. Foundations of colloid science. New York: Oxford University Press; 2001.

[23] Wallevik JE. Rheological properties of cement paste: thixotropic behavior and structural breakdown. Cem Concr Res 2009;39:14-29.

[24] Barnes HA. Thixotropy-a review. J Non-Newtonian Fluid Mech 1997;70:1-33.

[25] Banfill PFG. The rheology of fresh mortar. Mag Concr Res 1991;43:13-21.

[26] Lapasin R, Papo A, Rajgelj S. Flow behavior of fresh cement pastes. A comparison of different rheological instruments and techniques. Cem Concr Res 1983;13:349-56.

[27] Dzuy NQ Boger DV. Direct yield stress measurement with the vane method. J Rheol 1985;29:335-47.

[28] Billberg P. Form pressure generated by self-compacting concrete-influence of thixotropy and structural behaviour at rest, PhD Thesis, Royal institute of technology, Stockholm; 2006.

[29] Mewis J, Wagner NJ. Thixotropy. Adv Colloid Inter Sci 2009;147:214-27.

[30] Khayat KH, Saric-Coric M, Liotta F. Influence of thixotropy on stability characteristics of cement grout and concrete. ACI Mater J 2002;99:234-41.

[31] Assaad J, Khayat KH, Mesbah H. Variations of formwork pressure with thixotropy of self-consolidating concrete. ACI Mater J 2003;100:29-37. 
[32] Ovarlez G, Roussel N. A physical model for the prediction of lateral stress exerted by self-compacting concrete on formwork. Mater Struct 2006;39:269-79.

[33] Erdem TK, Khayat KH, Yahia A. Correlating rheology of self-consolidating concrete to corresponding concrete-equivalent mortar. ACI Mater J 2009;106:154-60.

[34] Feys D, Verhoeven R, De Schutter G. Influence of thixotropy on pressures required during pumping of concrete. In: Giacomin AJ, editor. Proceedings of the fifteenth international congress on rheology, American Institute of Physics, Monterey, CI 2088;710-2

[35] Khayat KH, Omran AF, Naji S, Billberg P, Yahia A. Field-oriented test methods to evaluate structural build-up at rest of flowable mortar and concrete. Mater Struct 2012;45:1547-64.

[36] Khayat KH, Assaad J. Effect of w/cm and high-range water-reducing admixture on formwork pressure and thixotropy of self-consolidating concrete. AC Mater J 2006;103:186-93.

[37] Assaad J, Khayat KH. Kinetics of formwork-pressure drop of self-consolidating concrete containing various types and contents of binder. Cem Concr Res 2005;35:1522-30.

[38] Assaad J, Khayat KH. Effect of coarse aggregate characteristics on lateral pressure exerted by Self-consolidating concrete. ACI Mater J 2005;102:145-53.

[39] Assaad J, Khayat KH. Effect of viscosity-enhancing admixtures on formwork pressure and thixotropy of self-consolidating concrete. ACI Mater J 2005;103:280-7.

[40] Assaad J, Khayat KH, Mesbah H. Assessment of thixotrophy of flowable and self-consolidating concrete. ACI Mater J 2003;100. p. 99-08.

[41] Roussel N, Ovarlez G, Garrault S, Brumaud C. The origins of thixotropy of fresh cement pastes. Cem Concr Res 2012;42:148-57.

[42] ASTM C150-12. Standard specification for portland cement. ASTM International; 2012
[43] ASTM C494-08. Standard specification for chemical admixtures for concrete. ASTM International; 2012.

[44] Khayat KH, Bickley J, Lessard M. Performance of air-entrained, self consolidating concrete for casting basement and foundation walls. ACI Mater 2000;97:374-80.

[45] Skarendahl A, Peterson So. Self-compacting concrete. State of the art report of RILEM TC174-SCC, France; 2000. p. 47-55.

[46] Legrand C. Contribution of study of the rheology of fresh concrete. doctoral thesis, Universite Paul Sabatier de Toulouse, France; 1971. p. 150.

[47] Ferraris CF, Obla KH, Hill R. The influence of mineral admixtures on the rhology of cement paste and concrete. Cem Concr Res 2001;31:245-55.

[48] Bentz DP, Ferraris CF, Galler MA, Hansen AS, Guynn JM. Influence of particle size distributions on yield stress and viscosity of cement-fly ash pastes. Cem Concr Res 2012;42:404-9.

[49] Cassagnabere F, Diederich P, Mouret M, Escadeillas G, Lachemi M. Impact of metakaolin characteristics on the rheological properties of mortar in the fresh state. Cem Concr Compos 2013;37. p. 95-07.

[50] Kucharska L, Moczko M. Influence of silica fume on the rheological properties of the matrices of high-performance concretes. Adv Cem Res 1994:24:710-7.

[51] Assaad J, Khayat KH. Formwork pressure of self consolidating concrete made with various binder types and contents. ACI Mater J 2005;102:215-23.

[52] Struble LJ. The rheology of fresh cement paste. Conf Am Ceram Soc 1991;16:7-29.

[53] Omran AF, Khayat KH. Choice of thixotropic index to evaluate formwork pressure characteristics of self-consolidating concrete. Cem Concr Res 2014:63:89-97.

[54] Zhang X, Han J. The effect of ultra-fine admixture on the rheological property of cement paste. Cem Concr Res 2000;30:827-30. 